\title{
Treatment of patients with transposition of great arteries and pulmonary vascular obstructive disease ${ }^{1}$
}

\author{
J. BYRNE ${ }^{2}$, D. CLARKE, J. F. N. TAYLOR, F. MACARTNEY, \\ M. DE LEVAL, AND J. STARK \\ From The Thoracic Unit, The Hospital for Sick Children, Great Ormond Street, London
}

SUMMARY Twenty-two patients with transposition of the great arteries with or without ventricular septal defect and one with double outlet right ventricle, d-malposition, and severe pulmonary vascular obstructive disease were treated surgically. All were cyanosed and had very limited exercise tolerance. Preoperatively, systemic arterial oxygen saturation $\left(\mathrm{SaO}_{2}\right)$ varied from 45 to 79 per cent (mean 65), haemoglobin was 13 to $23 \mathrm{~g} / \mathrm{dl}$ (mean 19). Pulmonary arteriolar resistance was 6.4 to 35 units $\mathrm{m}^{2}$ (mean 17). In the patients with a ventricular septal defect the Mustard operation was done without closure of the ventricular septal defect, and in the 3 patients with intact ventricular septum the Mustard operation was combined with creation of a ventricular septal defect. All patients survived the operation and improved. Postoperative $\mathrm{SaO}_{2}$ ranged from 75 to 96 per cent (mean 89) and haemoglobin from 10.6 to $17.8 \mathrm{~g} / \mathrm{dl}$ (mean 14.0). This improvement was significant $(\mathrm{P}<0.05)$. Five patients have had a postoperative cardiac catheterisation. The pulmonary arteriolar resistance remains high in all. Postoperative follow-up varies from 4 to 40 months (mean 14 months). So far there have been no late deaths and all patients remain improved.

Ferencz (1966) and Wagenvoort et al. (1968) described the development of pulmonary vascular obstructive disease in patients with transposition of the great arteries. The coexistence of a ventricular septal defect or persistent ductus arteriosus appears to accelerate the development of pulmonary vascular obstructive disease and a substantial number of patients with these associated lesions will have a fixed high pulmonary arteriolar resistance by the end of the first year of life (Viles et al., 1969; Newfeld et al., 1974).

When, in the past, patients with severely raised pulmonary arteriolar resistance have had the Mustard operation for redirection of venous inflow with closure of ventricular septal defect, the mortality has been high, and such patients have been considered inoperable (Mair et al., 1971). In addition, progression of pulmonary vascular obstructive disease may occur after the Mustard

${ }^{1}$ This work was presented in part at the 26th Annual Scientific Session of the American College of Cardiology, held in Philadelphia, U.S.A. March 1977 and was supported in part by British Heart Foundation Grant No. 583.

${ }^{2}$ Present address: 1060 East 1st South, Salt Lake City, Utah 84112, U.S.A.

Received for publication 27 June 1977 procedure and be a cause of late death (Mair et al., 1976). In 1972, Lindesmith introduced the concept of the palliative Mustard operation, in which the redirection of venous inflow is performed, but the ventricular septal defect is left open (Lindesmith et al., 1972). In 1975 an experience with 10 patients with no operative mortality and with substantial clinical improvement in each was reported (Lindesmith et al., 1975).

Although our present policy is to perform the Mustard operation at 8 to 12 months of age for simple transposition of the great arteries, and at 3 to 4 months for transposition plus ventricular septal defect (with closure of the ventricular septal defect) (Stark, 1976), we continue to see patients with severe pulmonary vascular disease. The purpose of this communication is to report our experience with 23 such patients, 20 of whom underwent Mustard's operation without closure of a coexisting ventricular septal defect, and 3 who had the Mustard operation with creation of a ventricular septal defect.

\section{Patients and methods}

Since October 1973, the palliative Mustard operation has been performed in 22 patients with transposition 
of the great arteries, whose ages ranged from $2 \frac{1}{2}$ to 17 years and weight from 8 to 42 kilograms. The first 12 patients have been presented previously (Stark et al., 1976b). Nineteen of these patients had a ventricular septal defect and 3 had an intact ventricular septum (Table 1). A palliative Mustard operation was also done in 1 patient with double outlet right ventricle and d-malposition.

Table 1 Diagnoses of patients who had 'palliative' Mustard operation

\begin{tabular}{lc}
\hline Diagnosis & No. \\
\hline TGA + VSD & 18 \\
TGA + VSD + PDA & 1 \\
DORV + VSD + d-malposition & 1 \\
TGA + IVS & 2 \\
TGA + IVS + PDA + coarctation & 1 \\
\hline Total & 23 \\
\hline
\end{tabular}

TGA, transposition of the great arteries; VSD, ventricular septal defect; PDA, persistent ductus arteriosus; DORV, double outlet right ventricle; IVS, intact ventricular septum.

The patients had undergone a total of 27 previous operations (Table 2). Three patients had had Blalock-Taussig shunts after banding of the pulmonary artery. These procedures were done before the early development of pulmonary vascular obstructive disease in transposition of the great arteries was fully appreciated, and the banding of the pulmonary artery was done too late. In 3 patients thoractomy only had been carried out: in one the planned Blalock-Taussig shunt was abandoned when the pulmonary artery pressure was found to be at systemic level; in another, attempted ligation of a persistent ductus arteriosus was abandoned when test occlusion produced haemodynamic instability; in the last patient, pulmonary artery banding was abandoned for the same reason.

Preoperative cardiac catheterisation was performed under sedation without general anaesthesia. In all patients pulmonary venous $\mathrm{PO}_{2}$ and $\mathrm{PCO}_{2}$ were within normal limits, confirming the validity of flow and resistance calculations. Oxygen saturation and pressures were recorded in all 4 cardiac

Table 2 Operations performed before 'palliative' Mustard (23 patients)

\begin{tabular}{lc}
\hline Previous operations & No. \\
\hline Blalock-Hanlon & 12 \\
Blalock-Taussig & 3 \\
Pulmonary artery banding & 7 \\
Ligation PDA & 1 \\
Repair coarctation & 1 \\
Thoractomy & 3 \\
\hline Total & 27 \\
\hline
\end{tabular}

chambers, the great arteries, venae cavae, and pulmonary veins. Flows were calculated using the Fick principle and an assumed oxygen consumption. Pulmonary arteriolar resistance was calculated from the mean pressure drop across the pulmonary circulation and the pulmonary blood flow corrected for body surface area (in units $\mathrm{m}^{2}$ ).

All 23 patients were cyanosed and had very limited exercise tolerance. Systemic arterial saturation varied from 45 to 79 (mean \pm 1 SD $65 \pm 11 \%$ ). Preoperative haemoglobin varied from 13.1 to $23.5 \mathrm{~g} / \mathrm{dl}(19 \cdot 2 \pm 3 \cdot 1 \mathrm{~g} / \mathrm{dl})$. Only one patient had a haemoglobin below $16 \mathrm{~g} / \mathrm{dl}$ and was relatively anaemic. Pulmonary arteriolar resistance $(16.7$ \pm 8.3 units $\mathrm{m}^{2}$ ) was below 8 units $\mathrm{m}^{2}$ in only one patient, and was as high as 35 units (Table 3 ).

Table 3 Pulmonary arteriolar resistance $(R p)$ calculated at cardiac catheterisation

\begin{tabular}{lc}
\hline$R p\left(\right.$ units $\left.m^{2}\right)$ & No. of patients \\
\hline$<8$ & 1 \\
$8-10$ & 3 \\
$>10$ & 19 \\
\hline Total & 23 \\
\hline
\end{tabular}

\section{Operation}

Operation was carried out using cardiopulmonary bypass, with hypothermia $\left(22\right.$ to $\left.28^{\circ} \mathrm{C}\right)$, intermittent aortic cross-clamping, and periods of decreased flow to lessen bronchial artery return. A trouser-shaped intra-atrial baffle was used (Stark, 1973). Pericardium was used in 21 patients and Dacron in 2. The pulmonary venous atrium was enlarged in 2 patients. Debanding and arterioplasty of the pulmonary artery, ligation of the persistent ductus arteriosus, and ligation of BlalockTaussig shunts were done in appropriate patients. The 3 patients with intact ventricular septum had a ventricular septal defect created via an apical left ventriculotomy, as previously described (Stark et al., 1976a). Intensive postoperative care did not differ from that after other open heart procedures. All patients were ventilated for at least 24 hours through a nasotracheal tube using an Engström ventilator.

\section{Results}

The patients were followed up in the clinics of The Hospital for Sick Children, and by communication with referring doctors. Arterial oxygen saturation was measured at least 3 months after operation in all patients, and haemoglobin at 
least 1 month after operation in 14 patients. Five patients have undergone postoperative catheterisation.

Pre- and postoperative data were compared using standard statistical methods (Snedecor and Cochran, 1967). As it has been shown that the palliative Mustard operation results in more than a simple reversal of pulmonary and systemic venous inflow (Mair et al., 1976), we analysed preoperative catheterisation data to find out whether there was any correlation between preoperative data and postoperative systemic arterial oxygen saturation. Stepwise regression analysis was used (Dixon, 1976). The dependent variables were postoperative systemic arterial oxygen saturation, the difference between this and preoperative pulmonary artery oxygen saturation, and the increase in systemic arterial oxygen saturation after operation. Independent variables included original values and logarithms of preoperative pulmonary arteriolar resistance, haemoglobin, pulmonary artery oxygen saturation, pulmonary arteriovenous oxygen difference, mean pulmonary artery pressure, mean aortic pressure, and the pulmonary/systemic pressure ratio.

All patients survived the operation. Artificial ventilation was used for 1 to 20 days (mean 3.7 days, median 2.0 days). Five patients required inotropic support after operation and one of these also required 3 days of peritoneal dialysis for transient renal failure. Two patients were reexplored for bleeding. One patient had a transient hemiparesis, presumably the result of an embolus which occurred on the 8th postoperative day; however, when last seen four months after operation, she was fully ambulatory and had only a mild residual neurological deficit.

Late follow-up ranges from 4 to 40 months (mean 14.1 months). There have been no late deaths. There have been no significant arrhythmias and no evidence of caval obstruction.

No patient is cyanotic and exercise tolerance has increased in all. One patient has chronic congestive heart failure, shown at postoperative cardiac catheterisation to be biventricular, but nevertheless remains better than before operation.

Postoperative systemic arterial saturation ( $\left.\mathrm{SaO}_{2}\right)$ ranged from 75 to 96 per cent (mean $89 \pm 5 \cdot 4 \%$ ) and is significantly greater than the preoperative $\mathrm{SaO}_{2}(\mathrm{P}<0.001)$. The $\mathrm{SaO}_{2}$ was improved in all patients; the increase in $\mathrm{SaO}_{2}$ varied from 6 to 48 per cent (mean $24 \pm 11.9 \%$ ); in only one patient was the increase less than 14 per cent. Postoperative haemoglobin ranged from 10.6 to $17.8 \mathrm{~g} / \mathrm{dl}(13.8 \pm 2.2 \mathrm{~g} / \mathrm{dl})$ in the 14 patients in whom it was measured. This value is significantly
Table 4 Pre- and postoperative arterial oxygen saturation $\left(\mathrm{SaO}_{2}\right)$ and haemoglobin $(\mathrm{Hb})$

\begin{tabular}{llllll}
\hline & $\begin{array}{l}\text { Preop } \\
\text { Range }\end{array}$ & Mean & $\begin{array}{l}\text { Postop } \\
\text { Range }\end{array}$ & Mean & $\begin{array}{l}\text { Significance of } \\
\text { change }\end{array}$ \\
\hline $\mathrm{SaO}_{2}(\%)$ & $45-79$ & 65 & $75-96$ & 89 & $\mathrm{P}<0.001$ \\
$\mathrm{Hb}(\mathrm{g} / \mathrm{dl})$ & $13-25$ & 19 & $11-18$ & 14 & $\mathrm{P}<0.05$ \\
\hline
\end{tabular}

lower than the preoperative value in these 14 patients $(P<0.05)$ (Table 4$)$.

The difference between postoperative systemic arterial saturation and preoperative pulmonary artery saturation ranged from -10 to +19 per cent (mean $7 \cdot 2 \pm 6 \cdot 3 \%$ ). The only preoperative variable which was found to correlate with postoperative $\mathrm{SaO}_{2}$ was pulmonary arteriovenous oxygen difference. There was a significant $(P<0.005)$ positive correlation between pulmonary arterial venous oxygen difference and the difference between the preoperative pulmonary artery saturation and postoperative systemic arterial oxygen saturation. This relation was not significantly different in those patients whose postoperative $\mathrm{SaO}_{2}$ was greater than 90 per cent, and those in whom it was less than 90 per cent (Fig.).

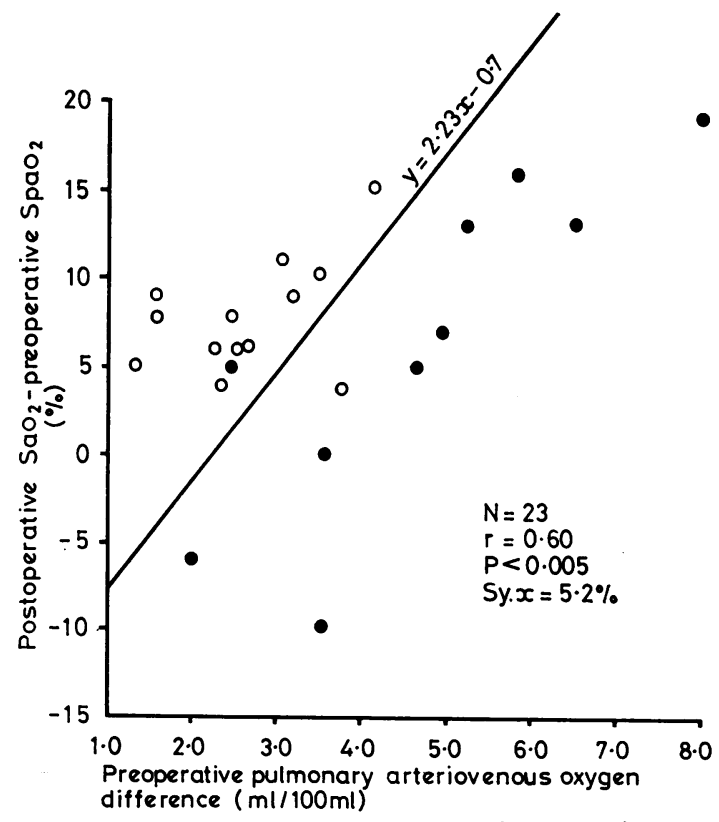

Figure Correlation between postoperative systemic arterial oxygen saturation minus preoperative pulmonary artery oxygen saturation and preoperative pulmonary arteriovenous oxygen difference. $=$ patients whose postoperative $\mathrm{SaO}_{2}$ was less than 90 per cent. 
Table 5 Cardiac catheterisation data before and after 'palliative' Mustard operation

\begin{tabular}{|c|c|c|c|c|c|c|c|c|c|}
\hline Case No. & $\begin{array}{l}\text { Preoperative } \\
\dot{Q}_{p} / Q_{s}\end{array}$ & $R p\left(u m^{2}\right)$ & $\begin{array}{l}\overline{P A}-\overline{L A} \\
(m m H g)\end{array}$ & $\mathrm{SaO}_{2}(\%)$ & $\begin{array}{l}\text { Months } \\
\text { postop }\end{array}$ & $\begin{array}{l}\text { Postoperative } \\
\phi_{p} / Q_{s}\end{array}$ & $R p\left(u m^{2}\right)$ & $\begin{array}{l}\overline{P A}-\overline{L A} \\
(m m H g)\end{array}$ & $\mathrm{SaO}_{2}(\%)$ \\
\hline $\begin{array}{l}1 \\
2 \\
3 \\
4 \\
5 \star\end{array}$ & $\begin{array}{l}1 \cdot 0: 1 \\
1 \cdot 4: 1 \\
0 \cdot 75: 1 \\
0 \cdot 5: 1 \\
0 \cdot 45: 1\end{array}$ & $\begin{array}{l}23 \\
17 \\
11 \cdot 8 \\
19 \\
8 \cdot 7\end{array}$ & $\begin{array}{l}86 \\
51 \\
47 \\
57 \\
21\end{array}$ & $\begin{array}{l}61 \\
65 \\
77 \\
65 \\
73\end{array}$ & $\begin{array}{r}9 \\
12 \\
14 \\
11 \\
9\end{array}$ & $\begin{array}{l}1 \cdot 5: 1 \\
0 \cdot 9: 1 \\
1 \cdot 2: 1 \\
2 \cdot 0: 1 \\
1 \cdot 6: 1\end{array}$ & $\begin{array}{l}15 \\
11 \cdot 8 \\
10 \cdot 3 \\
11 \cdot 7 \\
23\end{array}$ & $\begin{array}{l}68 \\
49 \\
48 \\
63 \\
85\end{array}$ & $\begin{array}{l}93 \\
82 \\
87 \\
93 \\
76\end{array}$ \\
\hline
\end{tabular}

Q́p/Q́s = pulmonary/systemic flow ratio.

$\overline{\mathrm{PA}}-\overline{\mathrm{LA}}=$ difference between mean pulmonary arterial and left atrial pressures.

$\star$ In Case 5 preoperative pulmonary artery pressure was recorded distal to pulmonary artery band.

All 5 of the patients studied postoperatively have raised pulmonary arteriolar resistance (Table 5). This is not unexpected and confirms the results of others (Lindesmith et al., 1975; Bernhard et al., 1976).

In one patient (case 5) in whom 3 years elapsed between preoperative and postoperative catheterisations the calculated pulmonary arteriolar resistance rose after operation; this may be accounted for by the presence of biventricular failure, with left ventricular end-diastolic pressure $22 \mathrm{mmHg}$.

\section{Discussion}

The development of pulmonary vascular disease in patients with transposition of the great arteries causes severe physiological consequences which are responsible for their clinical deterioration. Not only is pulmonary blood flow decreased, but mixing of pulmonary and systemic venous blood is decreased (Mair et al., 1976). Thus, there is further hypoxia and polycythaemia, decreased exercise tolerance, and the possibility of thromboembolic complications. The 'palliative' Mustard operation for transposition of the great arteries with pulmonary vascular obstructive disease as introduced by Lindesmith has resulted in substantial clinical improvement in all patients and appears to be a low risk operation in our experience as well as in that of others (Table 6).

After operation there was an increase in systemic arterial oxygen saturation in every patient, though it was only minimal in one. This increase in

Table 6 Mortality of 'palliative' Mustard operation in 4 reported series

\begin{tabular}{lrl}
\hline Authors & No. of patients & Mortality \\
\hline Lindesmith et al. (1975) & 10 & 0 \\
Mair et al. (1976) & 8 & 0 \\
Bernhard et al. (1976) & 8 & $1^{\star}$ \\
Present series (1977) & 23 & 0 \\
\hline Total & 49 & 1 \\
\hline
\end{tabular}

*Late death 8 months after operation. systemic arterial oxygen saturation is to be expected because the redirection of venous inflow increases effective pulmonary flow and also substantially decreases the volume of desaturated systemic venous blood which recirculates directly to the aorta. In 20 of our 23 patients, the postoperative systemic arterial oxygen saturation was in excess of the preoperative pulmonary artery saturation. These results substantiate those of others (Mair et al., 1976; Bernhard et al., 1976) and indicate that more than a simple reversal of pulmonary and systemic venous inflow has occurred after operation. This 'bonus' has been shown by Mair et al. (1976) to be the result of two factors: one is the increase in systemic resistance which occurs as a result of the increased arterial oxygen saturation. This would be expected to diminish the physiological right-to-left shunt occurring across the ventricular septal defect. The other factor is the increased saturation of systemic mixed venous blood resulting from the increased effective flow. Thus, whatever systemic venous blood recirculates to the aorta via the ventricular septal defect will have less effect on the resultant systemic arterial oxygen saturation. The ventricular septal defect probably serves to 'decompress' the left ventricle should the pulmonary resistance increase. In patients with an intact ventricular septum, a ventricular septal defect was created in the apical portion of the septum for this purpose.

The palliative Mustard operation is also useful in patients with double outlet right ventricle, malposition, and pulmonary vascular obstructive disease who are cyanotic because of unfavourable streaming (Bernhard et al., 1976). We observed a satisfactory result in one such patient. The palliative Mustard operation is currently indicated in those patients with pulmonary arteriolar resistance greater than 8 units $\mathrm{m}^{2}$. It has been shown that the operative mortality for patients with transposition of the great arteries, ventricular septal defect, and pulmonary arteriolar resistance more than 10 units $\mathrm{m}^{2}$ is very high; in one report 7 of 8 patients did not 
survive operation (Mair et al., 1976). Furthermore, in those who have severe pulmonary vascular obstructive disease but survive the Mustard operation with closure of the ventricular septal defect, the risk of late death caused by progressive pulmonary vascular obstructive disease may be increased.

Good results achieved with the palliative Mustard operation should not diminish our efforts to diagnose and treat all children with transposition of the great arteries early, before they develop a severe degree of pulmonary vascular obstructive disease.

\section{References}

Bernhard, W. F., Dick, M., Sloss, L. J., Castaneda, A. R., and Nadas, A. S. (1976). The palliative Mustard operation for double outlet right ventricle or transposition of the great arteries associated with ventricular septal defert, pulmonary arterial hypertension and pulmonary vascular obstructive disease; a report of 8 patients. Circulation, 54, 810-817.

Dixon, W. J. (1976). Stepwise Regression in BMD Biomedical Computer Programmes, p. 305 . University of California Press, Berkeley, Los Angeles and London.

Ferencz, C. (1966). Transposition of the great vessels; pathophysiologic considerations based upon a study of the lungs. Circulation, 33, 232-241.

Lindesmith, G. G., Stanton, R. E., Lurie, P. R., Takahishi, M., Tucker, B. L., Stiles, Q. R., and Meyer, B. W. (1975). An assessment of Mustard's operation as a palliative procedure for transposition of the great vessels. Annals of Thoracic Surgery, 19, 514-520.

Lindesmith, G. G., Stiles, Q. R., Tucker, B. L., Gallaher, M.E., Stanton, R. E., and Meyer, B. W. (1972). The Mustard operation as a palliative procedure. Fournal of Thoracic and Cardiovascular Surgery, 63, 75-80.
Mair, D. D., Ritter, D. G., Danielson, G. K., Wallace, R. B., and McGoon, D. C. (1976). The palliative Mustard operation; rationale and results. American fournal of Cardiology, 37, 762-768.

Mair, D. D., Ritter, D. G., Ongley, P. A., and Helmholz, H. F. (1971). Hemodynamics and evaluation for surgery of patients with complete transposition of the great arteries and ventricular septal defect. American fournal of Cardiology, 28, 632-640.

Newfeld, E. A., Paul, M. H., Muster, A. J., and Idriss, F. S. (1974). Pulmonary vascular disease in complete transposition of the great arteries: a study of 200 patients. American fournal of Cardiology, 34, 75-82.

Snedecor, G. W., and Cochran, W. G. (1967). Statistical Methods, 6th ed. Iowa State University Press, Ames, Iowa.

Stark, J. (1973). Primary definitive intracardiac operations in infancy; transposition of the great arteries. In Advances in Cardiovascular Surgery, pp. 101-125. Ed. by J. W. Kirklin. Grune and Stratton, New York.

Stark, J. (1976). Operation results for transposition of the great arteries. Advances in Cardiology, 17, 20-31.

Stark, J., de Leval, M., and Taylor, J. F. N. (1976a). Mustard operation and creation of ventricular septal defect in two patients with transposition of the great arteries, intact ventricular septum and pulmonary vascular disease. American fournal of Cardiology, 38, 524-527.

Stark, J., Saw, S., de Leval, M., and Taylor, J. F. N. (1976b). Mustard operation in patients with pulmonary vascular disease (abstract). British Heart fournal, 38, 317.

Viles, P. H., Ongley, P. A., and Titus, J. (1969). The spectrum of pulmonary vascular disease in transposition of the great arteries. Circulation, 40, 31-41.

Wagenvoort, C. A., Nauta, J., Van der Schaar, P. J., Weeda, H. W. H., and Wagenvoort, W. (1968). Pulmonary vasculature in complete transposition of the great vessels judged from lung biopsies. Circulation, 38, 746-754.

Requests for reprints to Dr J. Stark, Thoracic Unit, The Hospital for Sick Children, Great Ormond Street, London WCIN 3JH. 